\title{
Analysis on Cloud Computing Architectures
}

\author{
Prof. Dr. M E Purushoththaman ${ }^{1 *}$, Dr. B Bhavani2 \\ ${ }^{1}$ Professor of CSE, Anna University, Chennai, India \\ ${ }^{2}$ Associate Professor of CSE \& Dean $(R \& D)$, Chebrolu Engineering College, Guntur, India \\ Imittapuru@gmail.com, $\underline{2}$ bbhawani.bhavani@gmail.com
}

\begin{abstract}
-
Cloud computing is an evolving technique and emerged the entire IT industry in recent years. It transformed the IT landscape and brought the world in the hands of public. One can access the resources available on cloud on pay-as-you-use basis, like applications and infrastructure provided by cloud providers in the form of applications already deployed by cloud providers for use by the cloud users. These services are developed, tested and deployed before they brought into use. Another feature of cloud computing is its massive storage infrastructure made available for database and data supplied by the user. The cloud has several unique architectures and many more are still evolving. The services like SaaS, PaaS and the IaaS are deployed on private, public, community and hybrid clouds. In this paper we discuss the present developments in the cloud computing architecture and also try to present feasible guidance for further processing. Papers published in journals, conferences, white papers are analyzed. We attempt to identify, examine and explain the current trends and development in cloud computing architecture. However, only $13 \%$ of the papers examined discussed Others-as-a-Service, while only $26 \%$ of the papers reviewed considered issues relating to the major actors involved in cloud computing. This will beneficial to cloud providers, users, and researchers alike
\end{abstract}

Key words: Cloud Computing, IT Industry, As-a-Service, IaaS, PaaS, SaaS

\section{INTRODUCTION}

Cloud computing is a model for enabling universal, on-demand and convenient network access to a shared pool of configurable computing resources (e.g., networks, servers, storage, applications, and services) that can be rapidly provisioned and released with minimal management effort or service provider interaction" [1]. Cloud computing can be seen as network-enabled services that provide scalable, QoS guaranteed services on demand that can be accessed over the Internet [2]. Cloud computing allows for sharing of resources over the Internet. These resources are shared using infrastructure provided by a cloud service provider (CSP). The cloud consumer accesses the resources, which are scalable and ubiquitous, on-demand as-youuse and pay-as-you-go basis. Cloud computing also enables a level of abstraction between the required computing resource and the underlying architecture such as storage, network and services [2]. Cloud computing encompasses the client and server, and the three primary service delivery models. The cloud client comprises the software or hardware abstraction layer used for connection to the cloud services. Servers are used by the CSPs to provide the three primary services 
delivery types. There are several service delivery types, but the primary ones are Platform-as-aServices (PaaS), Infrastructure-as-a-Service (IaaS), and Software-as-a-Service (SaaS).

In PaaS provides a computing platform for use by the consumer through the infrastructure provided by a cloud service provider [3]. The user can develop, test and deploy an application using a CSP's platform. The user does not have to install software required for this purpose.

In IaaS, the CSP provides infrastructure in the form of servers, storage and computing resources for the consumer. The advantage of this is that the user does not have to invest in expensive IT infrastructure. Services are scalable and on-demand. Also, the customer utilizes and pays for what is consumed.

In SaaS, a CSP provides an application over the Internet for use by a customer [3]. In effect, the user does not have to purchase or install such applications. This provides a network-based access to software that is managed from a centralised location, and the customer has remote access [3].

There are basically four types of cloud development models: private, public, community and hybrid clouds. Private clouds are provided within an enterprise data centre. The organization has control over the cloud infrastructure and it is secured by and prevents the external access until permitted from the internal sources. Public cloud services are provided over the Internet by CSP using their own infrastructure. Scalable services are accessed on a pay-as-you-go (PAYG) payment model. Public clouds are considered less secured. Community cloud is cloud operated by several organizations possibly engaged in similar activities or purpose. The infrastructure could be hosted by a third party with an agreed policy in place for usage [3]. In recent times, cloud, edge and fog computing seem to be complimenting activities. Edge computing allows optimization of the cloud by processing data at the edge of a network instead of doing it in a cloud or a central data warehouse. Also known as fog computing or fogging, facilitates the operation of compute, storage and networking services between end devices and cloud computing data centres. The purpose of this paper is to discuss cloud computing architecture. The paper takes a look at the primary abstraction layers on which services are offered. In addition, advances in the industry in terms of cloud computing architecture will be highlighted. The remaining part of the paper is organized as follows: Section 2 deals with related work. Section 3 will focus on the main cloud architecture. Section 4 discuss the industry trend in cloud architecture. Section 5 concludes the paper and suggests future work.

\section{RELATED WORK}

In [4], private cloud computing and delegation of control is proposed. The aim was to examine issues in private clouds. The areas of pricing, regulations and data protection in terms of private cloud was discussed. This ensures an optimum benefit of such an investment in the long run. In [3], security in cloud computing: opportunities and challenges were presented. The approach examined several security issues. In addition, there was a brief discussion on cloud computing architectural framework. In [2], a review on cloud computing: design challenges in architecture and security is proposed. Various concepts relating to cloud computing architecture were examined in some details. Security concerns were also discussed with some solutions suggested. In [5], cloud computing - concepts, architecture and challenges were presented. The characteristics, benefits and issues in cloud computing were discussed. In [6], cloud computing: a 
study of Infrastructure-as-a-Service is postulated. The papers provide an understanding of IaaS in cloud computing. The roles of the provider and what is available to the consumer was also discussed. In [7], NIST cloud computing reference architecture provides a simple but detailed classification of most aspects of cloud computing. Almost everything about cloud computing is summarized in a crisp form. In [8], Cloud Computing Architecture is presented. The architecture is presented in terms of front end and back end. The front end involves the consumers, while the back end comprises the service providers. In [9], cloud architecture for the logistics business is proposed. The focus is on a cloud architecture to support logistics services. Various layers were proposed with the overall objective of cost reduction in logistics operations. In [10], cloud computing and inter-clouds - types, topologies and research issues is presented. The types of cloud services and deployment models were discussed. Thereafter, the need for inter-cloud and services that could be offered were examined. In [11], cloud computing security issues and challenges is presented. A survey of cloud services was carried out including deployment models. Thereafter, a taxonomy of cloud challenges was carried out. [12] proposed the use of Microsoft Azure hybrid cloud to implement an architecture for Software-as-a-Service (SaaS) model of content based image retrieval (CBIR). The focus is on digital images and CBIR in particular. The architecture allows a large set of images to be accessed and processed using the Microsoft Azure which is suitable for hybrid purposes. 1n [13], Cloud Services Architectures is proposed. The main focus is on the open cloud connect architecture. Various cloud interfaces were also described. In [14], Evaluation of mobile cloud architectures is proposed. The main focus of the work was to compare mobile architecture based on mobile cloud applications. In [15], multi-cloud Platform-as-a-Service model, functionalities and approaches is presented. The main focus is on multi-cloud architecture in terms of PaaS. Two models were proposed and discussed in the paper. [20] argue that the migration in private cloud will be (15\%) while compare the public migration up to (28\%) in the year 2019. In [24] the authors are sure for the cloud computing has its own conceptual, technical, economic and user experience characteristics. The service oriented, loose coupling, strong fault tolerant, business model and ease use are main characteristics of cloud computing. Clear insights into cloud computing will help the development and adoption of this evolving technology both for academe and industry. [26]Security consciousness and concerns arise as soon as one begins to run applications beyond the designated firewall and move closer towards the public domain. [30] discussed on most research projects focus on developing Inter-Cloud Federations, most industry projects provide services or libraries for direct provisioning and scheduling across clouds. Also, most research projects focus on SLA-based brokering, where as industry driven ones focus on TriggerAction based or directly managed brokering. [38] it provides a better understanding of the design challenges of cloud computing and identify important research directions in this increasingly important area.

\section{Cloud Computing Architecture}

\section{A. Describing the NIST Model}

According to NIST, five major actors have been identified in cloud computing [7]. The NIST Conceptual Reference Model diagram in [7] shows the actors which are discussed below. 
a. Cloud Consumer: A person or organization that starts and keeps a business association with and requires services from suppliers of cloud services [22].

b. Cloud Provider: A person, organization engaged in supplying cloud computing services to interested persons or organizations.

c. Cloud Auditor: An organization in charge of conducting independent evaluation of cloud computing, and determining the systems effectiveness and security.

d. Cloud Broker: A third-party organization or individual that serves as an intermediary between cloud consumers and cloud providers. He/she is useful for negotiating terms and conditions of the contract for the purchase of cloud services.

e. Cloud Carrier: An intermediary person, organization or entity that provides connectivity and transport of cloud services from cloud provider to cloud consumers.

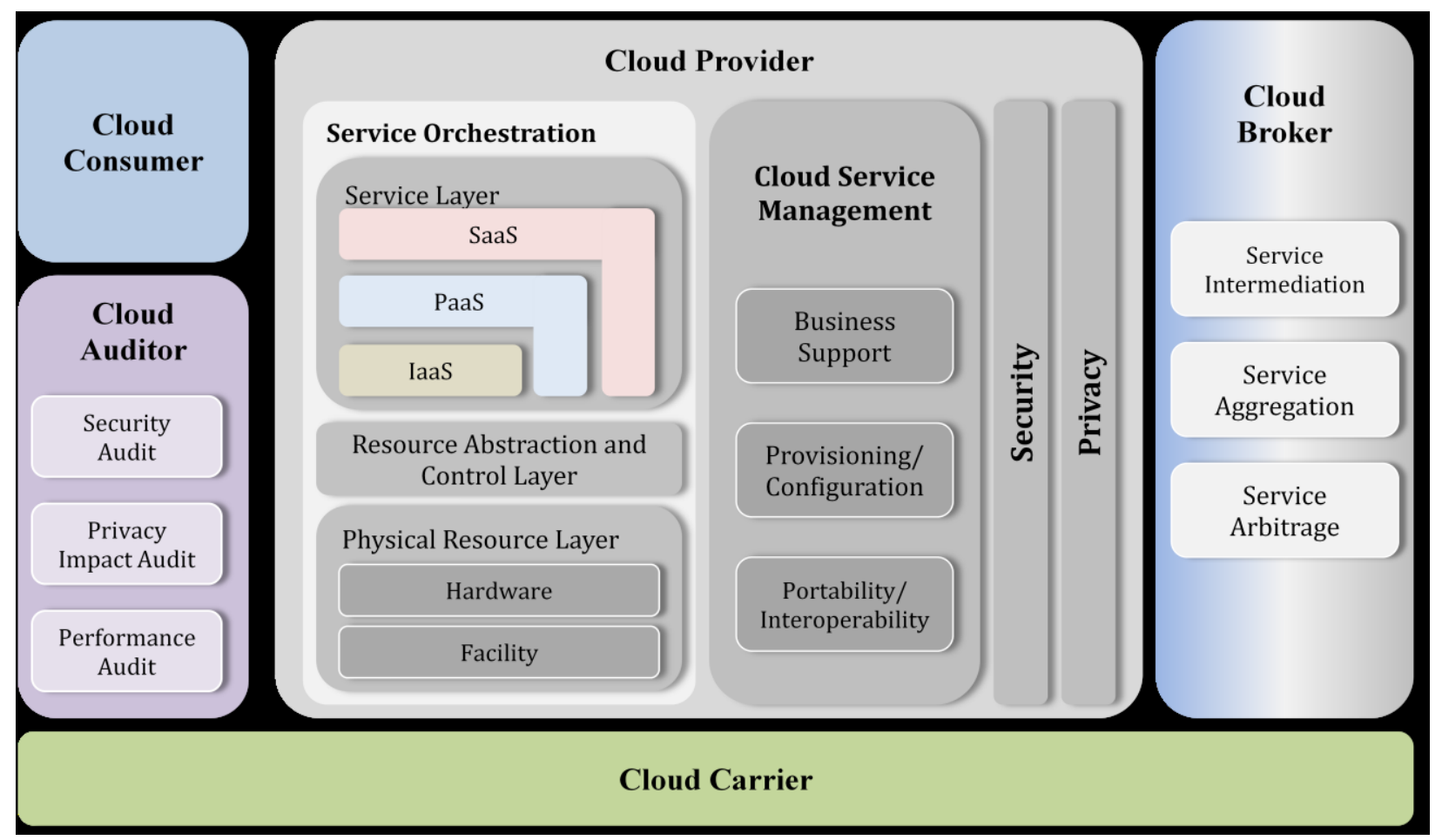

The diagram showing interactions between the actors in cloud computing in [7] describes the relationship amongst actors in cloud computing. Highlighting the relevance of each party in actualizing the delivery, use and maintenance of cloud services. In addition, NIST also provides five characteristics of the cloud [11]

a. On-demand self-service: Computing capabilities are allocated to users based on their predefined requirements. Capabilities such as server processing time and storage spaces are allocated automatically without human interference.

b. Broad Network Access: Thick or thin clients (ranging from tablets, laptops, workstations to mobile phones) enjoy access to the cloud by using standard mechanisms.

c. Resource pooling: Multi-tenant models pool together resources in order to provide services to multiple consumers. These services can be customised to satisfy the peculiarity of each consumers' requirements. 
d. Rapid Elasticity: This describes the cloud providers' ability to rapidly deploy scalable resources at the request of consumers. The cloud architecture must be able to seamlessly scale up and down amongst each requests of users, ensuring that the capabilities appear unlimited to the consumer.

e. Measured Service: The cloud provider monitors and controls certain aspects of the cloud service to ensure effective resource usage and overall predictive planning. This is achieved by the use of a metering capability embedded within the system.

\section{B. Cloud Computing Services}

A cloud architecture can be divided into the back end and front end. The front end is made visible to the user through connections to the Internet, allowing user interactions with the system [11]. The back end comprises the various cloud services models.

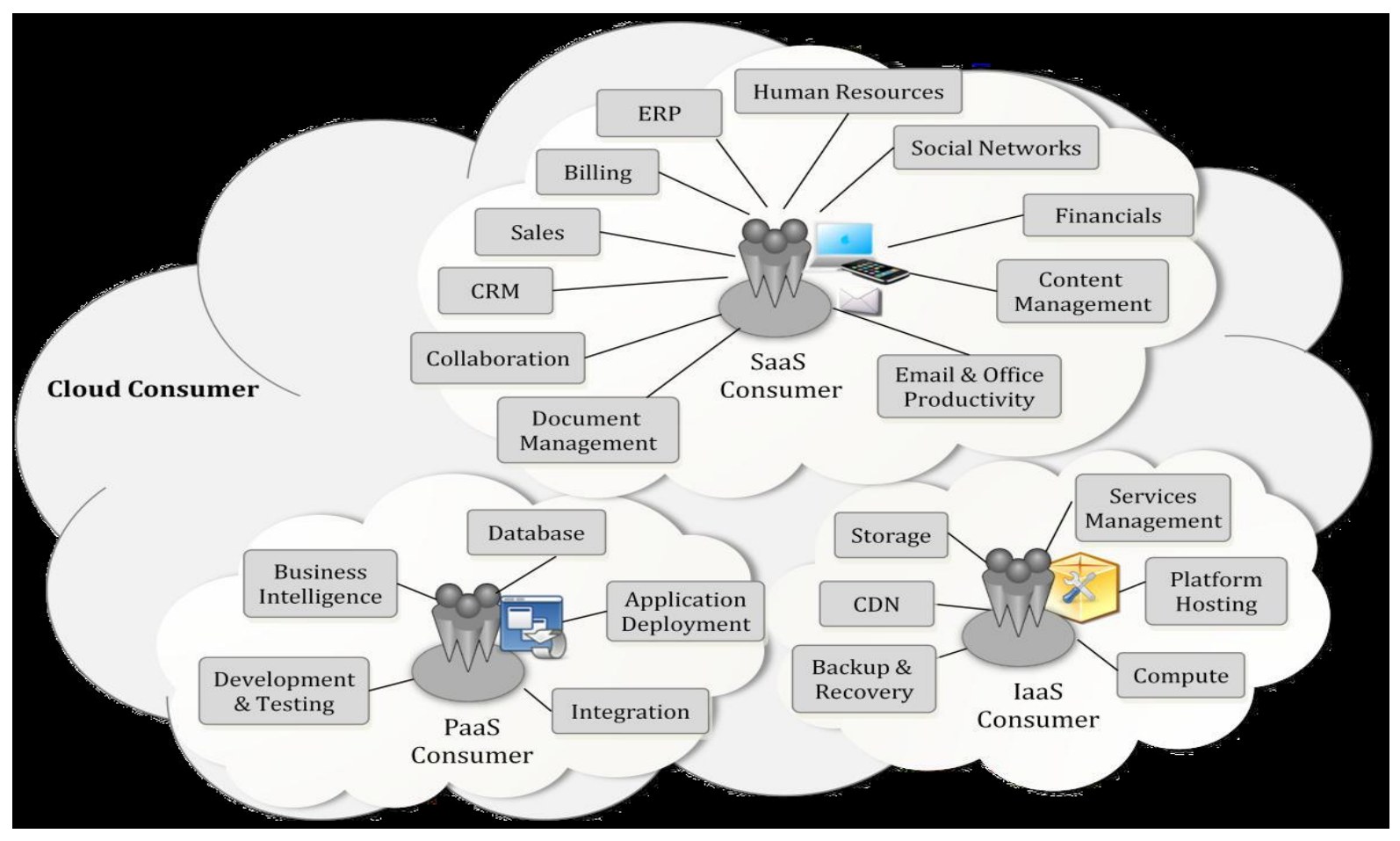

\section{1) Software-as-a-Service (SaaS)}

The user is offered a hosted set of software running on a platform and infrastructure owned by the cloud provider [2]. Applications are designed and developed to be simultaneously accessed by various cloud consumers over the Internet [11]. The hosted application is managed by the CSP, who maintains and ensures up-to-date running of the system. The hosted application supports multitenancy, it is available on demand and can be scaled up on down [11]. Some SaaS providers run on other cloud provider's PaaS or IaaS offerings [2]. 
Examples of SaaS [21]:

a. Email and Office Productivity: Email applications, word editors and processors, spreadsheets applications, presentations applications are typical examples in this category.

b. Billing: There are applications designed to monitor and manage customer billing. This is determined by users' system usage and subscriptions to products and services.

c. Customer Relationship Management (CRM): CRM are typical call-centre applications.

d. Financials: These are applications useful for tracking and reporting financial activities including processing of expenditure, generating invoices, payroll, and managing taxes.

\section{2) Platform-as-a-Service (PaaS)}

PaaS is a development service offered to the user through the Internet [2]. The user does not require any software installation or hardware requirements, thereby saving cost. It is a middleware upon which applications are built [11]. PaaS has built-in tools, built-in-security and web service interfaces for the deployed applications [11]. The deployed application can be integrated with other applications on the same platform and interfaced with other applications outside the platform [11]. PaaS has software comprising a database, middleware and development tools [2].

Examples of PaaS [21]:
a. Business Intelligence.
b. Database.
c. Development and Testing.
d. Integration.
e. Application Deployment.

\section{3) Infrastructure-as-a-Service.}

This is delivery of servers, storage, network and operating system, as a service [2]. IaaS provides an abstract machine with operating system already installed and configured [11]. IaaS enables data to be stored in different geographical locations. IaaS providers control activities in the cloud data centers while allowing users the flexibility to deploy and manage software services themselves [2]. The user has access to a virtual computer, storage, network infrastructure, computing resources for deploying and running software [6]. The cloud provider only manages the software and hardware, such as servers, storage devices, host OS and hypervisor for virtualization [5]. A typical cloud architecture diagram services available to cloud users is shown in [5].

Examples of IaaS [21]:

a. Content Delivery Networks (CDNs): CDNs record user content and files to improve the system performance such as speed and the cost associated with the delivery content for webbased systems. This is useful for handling diverse kinds of content for delivery to any website or mobile app. 
b. Backup and Recovery: This provides ability for seamless backup and restoration of files.

c. Compute: This involves server requirements for maintaining cloud systems that can be configured and provisioned dynamically.

d. Storage: Highly scalable storage ability useful for recording activities of applications, file backups and recovery and storing files are also available.

\section{Cloud Computing Deployment Types}

a. Private Cloud. A private cloud is exclusively setup and run for a particular enterprise, but third party organizations are given access to manage them on the behalf of the cloud owner [11]. The private cloud can be operated on-premise or off-premise. Private cloud has privacy, security and control. The cost and energy efficiency is also good [11]. Private clouds have limited scalability and are restricted to an area.

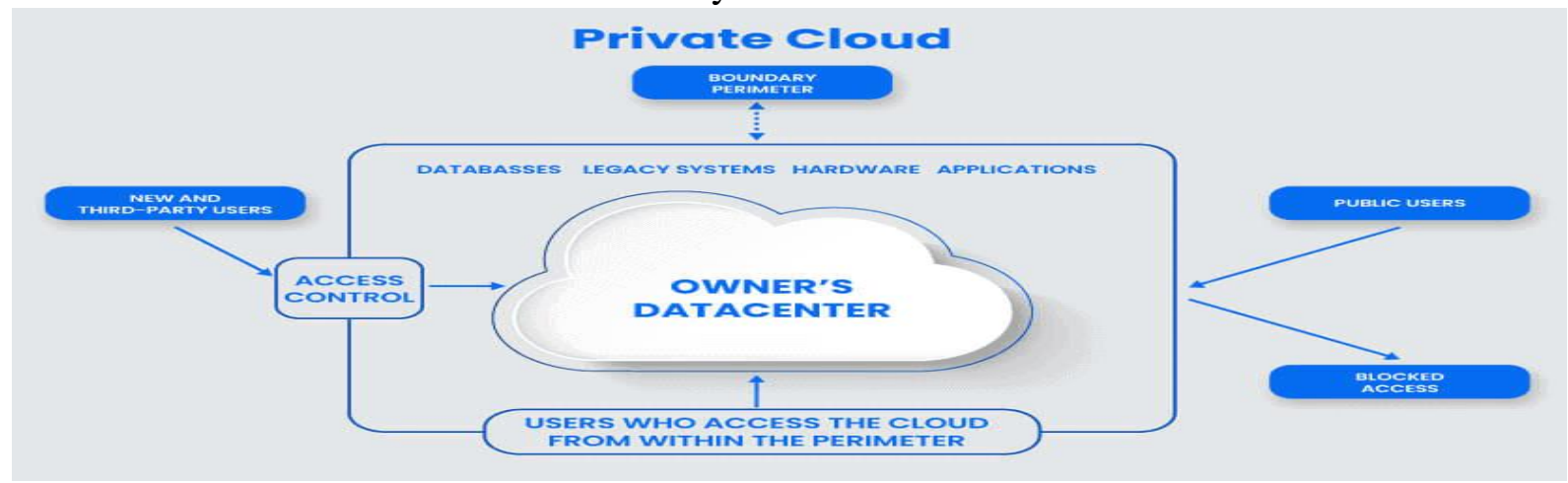

b. Public Cloud. They are operated by a CSP, who owns the infrastructure and data centers. The infrastructure is on premise and enterprises can access services on-demand and pay-as-you-go basis [11]. Services are made available to an organizations and users over a public network through a browser [3] [6]. Public clouds are location independent, reliable and highly scalable, but less secure and not customizable [11].

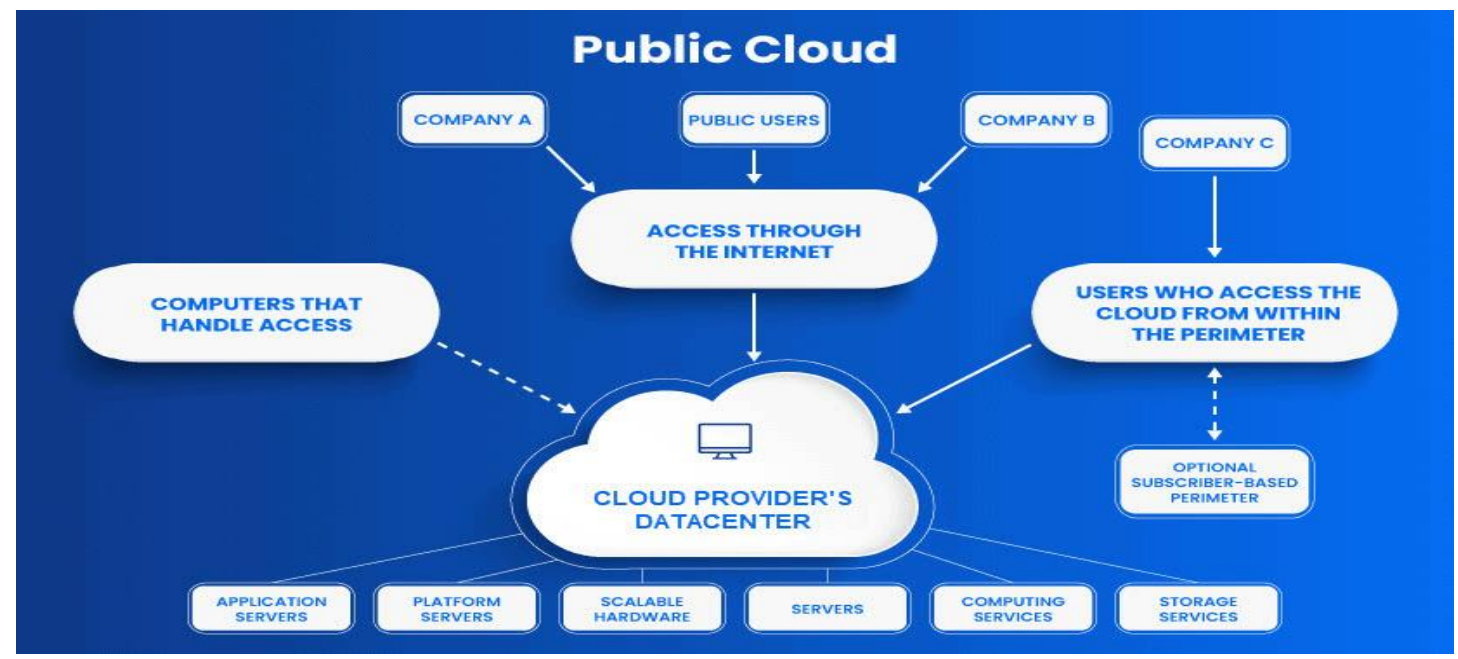

c. Community Cloud. Community cloud is hosted by several organizations or institutions 
sharing common interest. Typical examples are universities using it for learning and research. Organizations may decide to manage the cloud system themselves on site or off site and may also decide to outsource the daily running of the system to a third party organization [11].

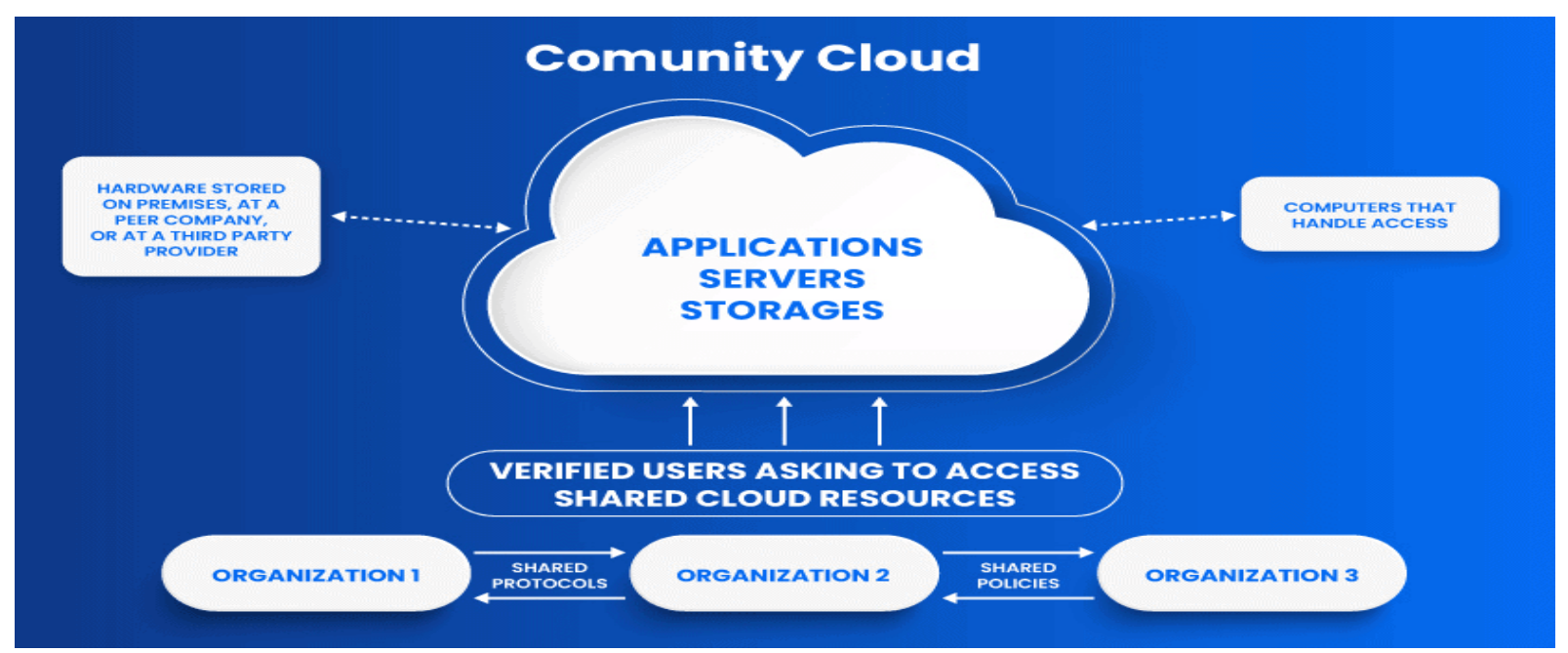

d. Hybrid Cloud. Hybrid Cloud represents a combination of either a selection or all cloud deployment types i.e. private, public or community cloud. Core activities are hosted on a private cloud, while less essential services are outsourced to a public cloud. Each of the cloud remains a unique entity, but linked together by standardized technology [11]. Hybrid clouds are subjected to network and security issues.

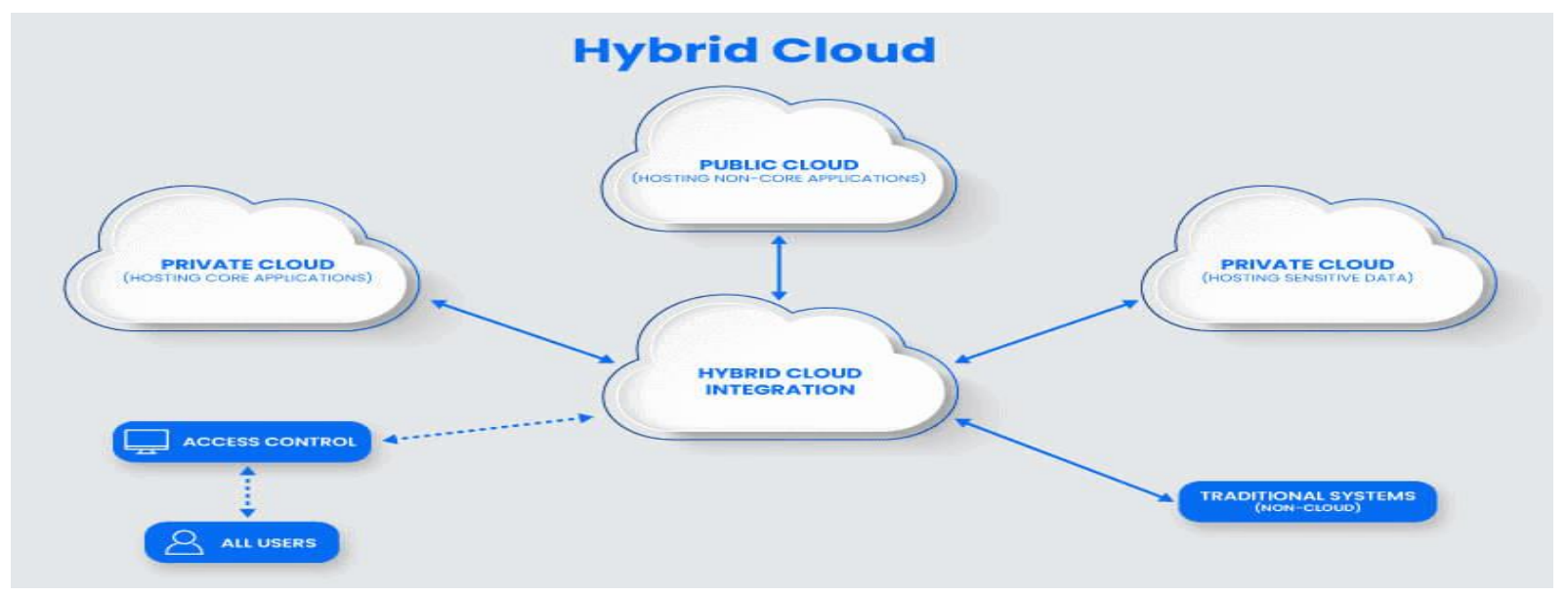

\section{Inter Cloud}

Inter cloud can be simply referred to as an interconnection of clouds, like the network of networks [11]. This allows connection of multiple cloud infrastructure to make more computing resources available. There are two types of inter-cloud: the federated cloud and Multi cloud.

a. Federation Cloud: A federation cloud is an inter-cloud setup where a set of cloud 
providers willfully combine their cloud infrastructure, this enables easy sharing of resources amongst the participating organizations. Every cloud provider voluntarily collaborates to exchange resources.

b. Multi-Cloud: Multi-cloud involves the use multiple independent cloud architecture acting as a single architecture. For example, organizations or enterprises could run a particular cloud activity that requires enormous resources on a private cloud and run other cloud activities requiring lower level of network resources or storage capability on a public cloud.

\section{INDUSTRY ARCHITECTURAL DEVELOPMENT}

\section{A. Hybrid Clouds}

According to Spectrum Enterprise, an organization's Information Technology structure is hybrid, except all of its structure is entirely based on physical infrastructure or entirely cloud based [16]. Research from Gartner predicts that by 2017, half of the main stream enterprises will have hybrid infrastructure. Hybrid cloud offers users easier access to and ability to manage private cloud solutions situated on premise. The hybrid cloud approach offers an organization the flexibility of evaluating resources for each job and then deciding the application that is most appropriate to execute the job [17]. An application with inconsistent rising and falling demand for network resources is best supported on the public cloud, while private clouds are most appropriate for applications requiring constant high levels of network resources. Hybrid cloud architectures may involve varying levels of sophistication. For example, some organizations and enterprises employ SaaS expenditure tracking application to seamlessly connect to their billing systems, which makes it a hybrid cloud approach.

\section{B. Private Clouds}

An attempt was made to resolve the confusion between IaaS private cloud and server virtualization environment in [18]. In cloud computing, virtualization is the foundation for all IaaS infrastructure and some tools can be used to manage the cloud just like a virtual data centre. On the other hand, the differences between an IaaS cloud environment and a virtual data centre are as follows [18]:

a. It is through standardization of environment that an enterprise can benefit from the cloud and lower cost.

b. Clouds are fully automated, hence all the standardized procedure will require the use of automated applications to enhance execution.

c. Clouds are self-service, hence every cloud consumer is provided access to particular workflow, which translates such approval into the permissions required by the user. Therefore, a provider must offer self-service.

d. There could be other cloud types apart from private cloud in an enterprise. However, multi-tenancy allows the private cloud to be properly isolated, while allowing high utilization of resources in a cost effective manner.

e. The cloud architecture can also be seen in terms of an IT portfolio with different 
deployment types and economics, degree of standardization and automation. An enterprise should expect only $15 \%$ of its application to be relevant for the present cloud and plan a gradually increase in percentage as events unfold.

f. It is better to start a private cloud on a small scale to allow for understanding. Moreover, it usually takes time before an organization can appreciate the benefits of the cloud. It is also better to maximize utilization rate before expanding.

g. The cloud is a shared environment and it better for the customers to ask for expansion to justify further investment in a cloud infrastructure.

\section{2016 Cloud Computing Survey [19]}

The review demonstrates that organizations have shown continued interest in migrating their IT activities and environment to the cloud utilizing a blend of public, private and hybrid cloud applications and solutions. The survey reported that the average company has migrated $45 \%$ of IT activities to the cloud, with $23 \%$ of this percentage of companies utilizing the private cloud, $15 \%$ in public cloud and $7 \%$ in hybrid cloud. The survey further highlighted that at the end of 2017 , the average company is expected to have migrated $59 \%$ of the IT activities to the cloud with $28 \%$ in private cloud, $22 \%$ in public cloud and $10 \%$ estimated to use hybrid cloud. The average company will allocate $45 \%$ of its cloud budget to SaaS, $30 \%$ to IaaS, $19 \%$ to PaaS and $6 \%$ to other emerging cloud models, such as network-as-a-service, and database-as-a-service, generally known as anything-as-a-service. It is estimated that large organizations plan to invest $21 \%$ of their budget to acquiring PaaS cloud services as compared to $17 \%$ of small and medium scale businesses (SMBs). On the contrary, SMBs are most likely going to spend over $75 \%$ of their financial plan on acquiring SaaS cloud services.

\section{2017 Cloud Migration Report [20]}

Statistics show expected rise of the use of public cloud among the companies surveyed by $28 \%$ year over year and private cloud is also expected to grow, but by a smaller percentage of (15\%). Public and private cloud usage is expected to grow even more than $49 \%$ and $18 \%$ respectively year over year for companies that employs more than 1,000 people.

\section{Analysis And Discussion}

Table shows several issues in cloud computing architecture and relevant work from several authors. Only one facet was used in this analysis, which are the core topics, discussed by these important authors. The authors are listed in no particular order. 
TABLE I

COMPARATIVE ANALYSIS OF ARCHITECTURE ISSUES

\begin{tabular}{|c|c|c|c|c|c|c|}
\hline AUTHOR and TITLE & 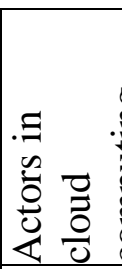 & 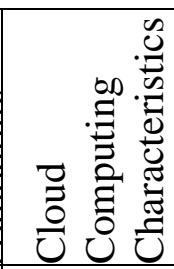 & 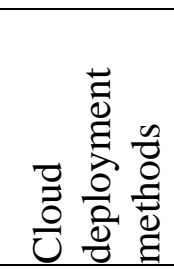 & 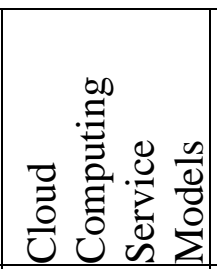 & 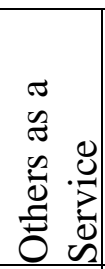 & 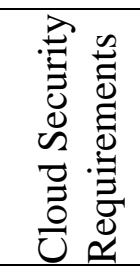 \\
\hline \begin{tabular}{l}
\multicolumn{1}{c}{ IDG Cloud } \\
Computing \\
Survey
\end{tabular} & & & $\mathrm{x}$ & $\mathrm{x}$ & $\bar{X}$ & \\
\hline CloudEndure, (2017) & & & $\mathrm{x}$ & & & \\
\hline C. W. Buyer (2012). & & & $\mathrm{x}$ & $\mathrm{x}$ & & \\
\hline $\begin{array}{l}\text { A. J. Ferrer; D. G. Pérez; and R. } \\
\text { S. González (2016) }\end{array}$ & & & $\mathrm{x}$ & $\mathrm{x}$ & & \\
\hline $\begin{array}{l}\text { J. Bou Abdo and J. Demerjian } \\
\text { (2017). }\end{array}$ & & & & & & \\
\hline M. Toy (2015) & $X$ & & & $\mathrm{x}$ & & \\
\hline A. Verma and S. Kaushal (2011) & & $\mathrm{x}$ & $\mathrm{x}$ & $\mathrm{x}$ & & $\mathrm{X}$ \\
\hline $\begin{array}{l}\text { M. Meena, A. R. Singh, and V. } \\
\text { A. Bharadi (2016) }\end{array}$ & & & & $\mathrm{x}$ & & \\
\hline F. Lui et al (2011) & $\mathrm{X}$ & $\mathrm{x}$ & $\mathrm{x}$ & $\mathrm{x}$ & & $\mathrm{X}$ \\
\hline $\begin{array}{l}\text { B. K. Rani, B. P. Rani, and A. } \\
\text { V. Babu (2015) }\end{array}$ & & $\mathrm{x}$ & $\mathrm{x}$ & $\mathrm{x}$ & & \\
\hline G. Niharika and V. Ritu (2015) & & & & & $\mathrm{X}$ & \\
\hline $\begin{array}{l}\text { R. Dhakar, A. Gupta, and A. } \\
\text { Vijay (2009) }\end{array}$ & & $\mathrm{x}$ & & $\mathrm{x}$ & & \\
\hline $\begin{array}{l}\text { S. Bhardwaj, L. Jain, and S. Jain } \\
\text { (2010) }\end{array}$ & $\mathrm{X}$ & $\mathrm{x}$ & & $\mathrm{x}$ & & \\
\hline Y. Jadeja and K. Modi, (2012) & & & $\mathrm{x}$ & $\mathrm{x}$ & & \\
\hline $\begin{array}{l}\text { V. Davidovic, D. Ilijevic, V. } \\
\text { Luk, and I. Pogarcic (2015) }\end{array}$ & & & $\mathrm{x}$ & $\mathrm{x}$ & & \\
\hline $\begin{array}{l}\text { M. Ali, S. U. Khan, and A. V } \\
\text { Vasilakos (2015) }\end{array}$ & & $\mathrm{x}$ & $\mathrm{x}$ & $\mathrm{x}$ & & $\mathrm{X}$ \\
\hline F. Hu et al. (2011) & $X$ & & $\mathrm{x}$ & $\mathrm{x}$ & & $\mathrm{X}$ \\
\hline P. Mell and T. Grance (2011) & & $\mathrm{x}$ & $\mathrm{x}$ & $\mathrm{x}$ & & \\
\hline $\begin{array}{l}\text { Cloud Taxonomy, } \\
\text { http://cloudtaxonomy.opencrowd.c } \\
\text { om/ }\end{array}$ & & & & $\mathrm{x}$ & & \\
\hline $\begin{array}{l}\text { R. B. Bohn, J. Messina, F. Liu, } \\
\text { J. Tong, and J. Mao (2011) }\end{array}$ & $\mathrm{X}$ & $\mathrm{x}$ & $\mathrm{x}$ & $\mathrm{x}$ & & \\
\hline Marissa Comeau (2014) & & & $\mathrm{x}$ & & & \\
\hline $\begin{array}{l}\text { Y. Amanatullah, C. Lim, H. P. } \\
\text { Ipung, and A. Juliandri (2013) }\end{array}$ & $\mathrm{X}$ & & & $\mathrm{x}$ & $\mathrm{x}$ & \\
\hline
\end{tabular}




\begin{tabular}{|c|c|c|c|c|c|c|}
\hline $\begin{array}{l}\text { C. Gong, J. Liu, Q. Zhang, H. } \\
\text { Chen, and Z. Gong (2010) }\end{array}$ & & $\mathrm{x}$ & & $\mathrm{X}$ & & \\
\hline $\begin{array}{l}\text { H. Takabi, J. B. D. Joshi, and G. } \\
\text { J. Ahn (2010) }\end{array}$ & & $\mathrm{x}$ & $\mathrm{X}$ & $\mathrm{X}$ & & $\mathrm{X}$ \\
\hline $\begin{array}{l}\text { S. Ramgovind, M. M. Eloff, and } \\
\text { E. Smith (2010) }\end{array}$ & & & $\mathrm{x}$ & $\mathrm{x}$ & & $\mathrm{X}$ \\
\hline $\begin{array}{l}\text { M. Hogan, F. Liu, A. Sokol, and } \\
\text { J. Tong (2011) }\end{array}$ & $\mathrm{X}$ & $\mathrm{x}$ & $\mathrm{x}$ & $\mathrm{X}$ & & $\mathrm{X}$ \\
\hline D. Chen and H. Zhao (2012) & & $\mathrm{x}$ & $\mathrm{x}$ & $\mathrm{x}$ & & $\mathrm{X}$ \\
\hline $\begin{array}{c}\text { S. Kächele, C. Spann, F. J. } \\
\text { Hauck, and J. Domaschka (2013) }\end{array}$ & & & & $\mathrm{X}$ & $\mathrm{x}$ & \\
\hline N. Grovez, R. Buyya, (2012). & & $\mathrm{x}$ & $\mathrm{x}$ & $\mathrm{x}$ & & \\
\hline $\begin{array}{l}\text { T. Dillon, C. W. C. Wu, and E. } \\
\text { Chang (2010) }\end{array}$ & & $\mathrm{X}$ & $\mathrm{X}$ & $\mathrm{X}$ & & \\
\hline $\begin{array}{l}\text { M. A. AlZain, E. Pardede, B. } \\
\text { Soh, and J. A. Thom (2012). }\end{array}$ & & $\mathrm{x}$ & $\mathrm{x}$ & $\mathrm{X}$ & & $\mathrm{X}$ \\
\hline $\begin{array}{l}\text { B. P. Rimal, E. Choi, and I. } \\
\text { Lumb (2009) }\end{array}$ & & & & $\mathrm{x}$ & $\mathrm{x}$ & \\
\hline $\begin{array}{l}\text { Y. Singh, F. Kandah, and W. } \\
\text { Zhang (2011) }\end{array}$ & $\mathrm{X}$ & & & & & \\
\hline $\begin{array}{l}\text { D. Wu, J. L. Thames, D. W. } \\
\text { Rosen, and D. Schaefer, } \\
\text { "DETC2012-70780," 2012, no. 1, } \\
\text { pp. 1-14. }\end{array}$ & $\mathrm{X}$ & $\mathrm{x}$ & & $\mathrm{X}$ & & \\
\hline $\begin{array}{l}\text { L. M. Vaquero, L. Rodero- } \\
\text { Merino, J. Caceres, and M. } \\
\text { Lindner (2008) }\end{array}$ & $X$ & $\mathrm{x}$ & & $\mathrm{x}$ & & \\
\hline $\begin{array}{l}\text { S. Subashini and V. Kavitha } \\
\text { (2011) }\end{array}$ & & $\mathrm{x}$ & $\mathrm{x}$ & $\mathrm{x}$ & & $\mathrm{X}$ \\
\hline $\begin{array}{l}\text { Q. Zhang, L. Cheng, and R. } \\
\text { Boutaba (2010). }\end{array}$ & $\mathrm{X}$ & & $\mathrm{x}$ & $\mathrm{X}$ & & $\mathrm{X}$ \\
\hline $\begin{array}{l}\text { R. Buyya, R. Ranjan, and R. N. } \\
\text { Calheiros (2010) }\end{array}$ & & & & $\mathrm{x}$ & & \\
\hline
\end{tabular}

\section{1) Major Actors Involved in Cloud Computing}

[7] Identifies the significant actors involved in cloud computing as, cloud consumer, cloud provider, cloud broker, cloud auditor, and the carrier. [7] also describes a typical interaction between actors in the system; a cloud consumer could request for cloud services directly from a cloud provider or through a cloud broker. However, [23] claims that there are 6 major actors in cloud computing and that each has its own activities, requirements and responsibilities. [23] opined that a cloud developer is the additional actor missing in other works. From the analysis, only $26 \%$ of the papers reviewed considered issues relating to the major actors involved in cloud computing. 


\section{2) Characteristics of Cloud Computing}

[11] Wrote that the characteristics of cloud computing includes; on demand self-service, broad network access, resource pooling, rapid elasticity, and measured service, while about $50 \%$ of the papers examined focuses on this topic.

\section{3) Cloud Deployment Methods}

From the Table, it can be seen that $62 \%$, which represents 22 of the 35 reviewed papers, discussed the various available cloud deployment methods. Some of them highlighted the merits and demerits of the various methods, and the majority concluding that the peculiarity of the demands of the cloud consumer would determine which is best to use.

\section{4) Cloud Computing Service Models}

Cloud computing service models was also discussed extensively in over $94 \%$ of the reviewed papers, revealing that knowledge about PaaS, IaaS and SaaS are in abundance.

\section{5) Others-as-a-Service}

Backup-as-a-service, storage-as-a-service, logistics-as-a-service, operating systems as a service(OSaaS), framework as a service(FaaS), database as a service(DaaS), network as a service(NaaS) and other models apart from the 3 primary ones were discussed in [19], [9], [23], [29] and [33]. Instead of performing backup with a centralized, on-premises IT department, BaaS connects systems to a private, public or hybrid cloud managed by the outside provider. In OSaas, instead of software, it's the operating system that is offered as the service. Customers pay on a per server basis for the automatic upgrade service. While in FaaS, it is not a finished product like $\mathrm{SaaS}$, it requires less work to implement than a full PaaS system. DBaaS is a cloud computing service model that provides users with some form of access to a database without the need for setting up physical hardware, installing software or configuring for performance. NaaS is a business model for delivering enterprise-wide area network services virtually on a subscription basis. However, only $13 \%$ of the papers examined discussed Others-as-a- Service.

\section{CONClusion}

Evolving by carrying its own advantages and disadvantages, cloud computing proved a better technology so far in connecting the people on globe and provide services as they demand. Cloud computing made the users free from worrying about infrastructure, platform and software development on their own purposes. By using the software and tools available on cloud they develop their applications by using the principle of "pay for use". As usual the budget allocation for "SaaS" is more than the other two services and more research work is suggested or expected on "Others-as-a- service" models. Since the cloud computing is not the final technique to satisfy the world of IT the sky computing is going to compel the users to turn their attention and at least one of the big cloud providers need to make the first move towards building the compatibility and inter-cloud layers. Like the distinguished professors who guessed the ruling of cloud computing in the year 2009, we also expect that which big CSP will tie the knot for 
interoperability of the clouds. Time only can tell whether it will be Google or Microsoft or Amazon.

\section{REFERENCES}

[1] P. Mell and T. Grance, "The NIST Definition of Cloud Computing Recommendations of the National Institute of Standards and Technology," Natl. Inst. Stand. Technol. Inf. Technol. Lab., vol. 145, p. 7, 2011.

[2] F. Hu et al., "A review on cloud computing: Design challenges in architecture and security," Journal of Computing and Information Technology, vol. 19, no. 1. pp. 25-55, 2011.

[3] M. Ali, S. U. Khan, and A. V Vasilakos, "Security in cloud computing: Opportunities and challenges," Inf. Sci. (Ny)., vol. 305, pp. 357-383, 2015.

[4] V. Davidovic, D. Ilijevic, V. Luk, and I. Pogarcic, "Private Cloud Computing and delegation of control," in Energy Procedia, 2015, vol. 100, no. C, pp. 196-205.

[5] Y. Jadeja and K. Modi, "Cloud computing - Concepts, architecture and challenges, " in 2012 International Conference on Computing, Electronics and Electrical Technologies, ICCEET 2012, 2012, no. November, pp. 877-880.

[6] S. Bhardwaj, L. Jain, and S. Jain, "Cloud Computing: a Study of Infrastructure As a Service (Iaas)," International Journal of Engineering., vol. 2, no. 1, pp. 60-63, 2010.

[7] F. Lui et al., "NIST Cloud Computing Reference Architecture: Recommendations of the National Institute of Standards and Technology," NIST Spec. Publ. 500-292, p. 35, 2011.

[8] R. Dhakar, A. Gupta, and A. Vijay, "Cloud Computing Architecture," Chinacloud.Cn, vol. 40, pp. 29-53, 2009.

[9] G. Niharika and V. Ritu, "Cloud architecture for the logistics business," in Procedia Computer Science, 2015, vol. 50, pp. 414-420.

[10] B. K. Rani, B. P. Rani, and A. V. Babu, "Cloud Computing and Inter-Clouds - Types, Topologies and Research Issues, ” Procedia Comput. Sci., vol. 50, pp. 24-29, 2015.

[11] Verma and S. Kaushal, "Cloud Computing Security Issues and Challenges: A Survey,” no. July, 2011, pp. 445-454.

[12] M. Meena, A. R. Singh, and V. A. Bharadi, "Architecture for Software as a Service (SaaS) Model of CBIR on Hybrid Cloud of Microsoft Azure, " in Procedia Computer Science, 2016, vol. 79, pp. 569-578.

[13] M. Toy, “Cloud Services Architectures,” in Procedia Computer Science, 2015, vol. 61, pp. 213-220.

[14] J. Bou Abdo and J. Demerjian, "Evaluation of mobile cloud architectures," Pervasive Mobile Computing, vol. 39, pp. 284-303, 2017.

[15] J. Ferrer, D. G. Pérez, and R. S. González, "Multi-cloud Platform-as-a-service Model, Functionalities and Approaches, " in Procedia Computer Science, 2016, vol. 97, pp. 63-72.

[16] Spectrum Enterprise (2016) "10 Things You Need to Know About Hybrid Cloud", TechNavio, "Global Hybrid Cloud Market,", available at http://www.technavio.com/report/global-hybrid-Cloud-market-2015-2019.

[17] Marissa Comeau (2014) "Hybrid cloud: What it is, what it does and hybrid cloud use cases" TechTarget Publication. Available at http://searchservervirtualization.techtarget.com/tip/Hybridcloud-What-it-is-what-it-does-and-hybrid-cloud-use-cases.

[18] C. W. Buyer, "Private cloud: get it right and exploit its energy economics, " pp. 1-6, 2012. 
[19] IDG Enterprise. (2017). 2016 IDG Enterprise Cloud Computing Survey. [online] Available at: https://www.idgenterprise.com/resource/research/2016-idg-enterprise-cloud-computingsurvey.

[20] CloudEndure, “2017 Cloud Migration Survey Report Benchmarks, Trends, ” 2017.

[21] Cloud Taxonomy, http://cloudtaxonomy.opencrowd.com

[22] R. B. Bohn, J. Messina, F. Liu, J. Tong, and J. Mao, "NIST cloud computing reference architecture," in Proceedings - 2011 IEEE World Congress on Services, SERVICES 2011, 2011, no. July 2011, pp. 594-596.

[23] Y. Amanatullah, C. Lim, H. P. Ipung, and A. Juliandri, "Toward Cloud Computing Reference Architecture: Cloud Service Management Perspective,” Int. Conf. ICT Smart Soc., no. June, pp. 1-4, 2013.

[24] C. Gong, J. Liu, Q. Zhang, H. Chen, and Z. Gong, "The characteristics of cloud computing," in Proceedings of the International Conference on Parallel Processing Workshops, 2010, pp. 275-279.

[25] H. Takabi, J. B. D. Joshi, and G. J. Ahn, "Security and privacy challenges in cloud computing environments, " IEEE Secur. Priv., vol. 8, no. 6, pp. 24-31, 2010.

[26] S. Ramgovind, M. M. Eloff, and E. Smith, "The management of security in Cloud computing," 2010 Inf. Secur. South Africa, pp. 1-7, 2010.

[27] M. Hogan, F. Liu, A. Sokol, and J. Tong, "NIST Cloud Computing Standards Roadmap," 2011.

[28] D. Chen and H. Zhao, "Data Security and Privacy Protection Issues in Cloud Computing," in 2012 International Conference on Computer Science and Electronics Engineering, 2012, no. 973, pp. 647-651.

[29] S. Kächele, C. Spann, F. J. Hauck, and J. Domaschka, "Beyond IaaS and PaaS: An extended cloud taxonomy for computation, storage and networking," in Proceedings - 2013 IEEE/ACM 6th International Conference on Utility and Cloud Computing, UCC 2013, 2013, pp. $75-82$.

[30] N. Grovez, R. Buyya, "Inter-Cloud architectures and application brokering: taxonomy and survey, 2012.

[31] T. Dillon, C. W. C. Wu, and E. Chang, "Cloud Computing: Issues and Challenges, " Adv. Inf. Netw. Appl. (AINA), 2010 24th IEEE Int. Conf., pp. 27-33, 2010.

[32] M. A. AlZain, E. Pardede, B. Soh, and J. A. Thom, "Cloud computing security: From single to multi-clouds," in Proceedings of the Annual Hawaii International Conference on System Sciences, 2012, pp. 5490-5499.

[33] B. P. Rimal, E. Choi, and I. Lumb, "A taxonomy and survey of cloud computing systems, " in NCM 2009 - 5th International Joint Conference on INC, IMS, and IDC, 2009, pp. 44-51.

[34] Y. Singh, F. Kandah, and W. Zhang, "A secured cost-effective multi-cloud storage in cloud computing," in 2011 IEEE Conference on Computer Communications Workshops, INFOCOM WKSHPS 2011, 2011, pp. 619-624.

[35] D. Wu, J. L. Thames, D. W. Rosen, and D. Schaefer, “DETC2012-70780,” 2012, no. 1, pp. $1-14$.

[36] L. M. Vaquero, L. Rodero-Merino, J. Caceres, and M. Lindner, "A break in the clouds," ACM SIGCOMM Comput. Commun. Rev., vol. 39, no. 1, p. 50, 2008.

[37] S. Subashini and V. Kavitha, "A survey on security issues in service delivery models of cloud computing," Journal of Network and Computer Applications, vol. 34, no. 1. Elsevier, pp. 1$11,2011$. 
[38] Q. Zhang, L. Cheng, and R. Boutaba, "Cloud computing: State-of-the-art and research challenges," J. Internet Serv. Appl., vol. 1, no. 1, pp. 7-18, 2010.

[39] R. Buyya, R. Ranjan, and R. N. Calheiros, "InterCloud: Utility-oriented federation of cloud computing environments for scaling of application services, " in Lecture Notes in Computer Science (including subseries Lecture Notes in Artificial Intelligence and Lecture Notes in Bioinformatics), 2010, vol. 6081 LNCS, no. PART 1, pp. 13-31.

[40] Isaac Odun-Ayo, Member, IEEE, Sanjay Misra, Member, IEEE, and Frank Agono " Cloud Computing Architecture: A Critical Analysis 